\title{
Characteristics and Clinical Outcomes of Non-small Cell Lung Cancer Patients in Korea With MET Exon 14 Skipping
}

\author{
JOON YOUNG HUR ${ }^{1}$, BO MI KU ${ }^{2}$, JOON HO SHIM ${ }^{3,4}$, HYUN AE JUNG ${ }^{1}$, JONG-MU SUN ${ }^{1}$, \\ SE-HOON LEE ${ }^{1}$, JIN SEOK AHN ${ }^{1}$, KEUNCHIL PARK ${ }^{1}$ and MYUNG-JU AHN ${ }^{1}$ \\ ${ }^{1}$ Division of Hematology-Oncology, Department of Medicine, Samsung Medical Center, \\ Sungkyunkwan University School of Medicine, Seoul, Republic of Korea; \\ ${ }^{2}$ Research Institute for Future Medicine, Samsung Medical Center, \\ Sungkyunkwan University School of Medicine, Seoul, Republic of Korea; \\ ${ }^{3}$ Department of Health Sciences and Technology, Samsung Advanced Institute of Health Science and Technology, \\ Sungkyunkwan University, Seoul, Republic of Korea; \\ ${ }^{4}$ Samsung Genome Institute, Samsung Medical Center, \\ Sungkyunkwan University School of Medicine, Seoul, Republic of Korea
}

\begin{abstract}
Background/Aim: MET exon 14 skipping occurs in 3-4\% of patients with lung adenocarcinomas. In this study, we performed a comprehensive analysis of clinical data from Korean non-small cell lung cancer (NSCLC) patients with MET exon 14 skipping. Patients and Methods: Overall, 1,020 patients diagnosed with NSCLC between January 2015 and July 2017 were analyzed by next-generation sequencing. Results: MET exon 14 skipping was identified in 20 NSCLC patients (1.9\%). The median age was 69 years (range $=39$. 86 years), $60.0 \%$ were male, and most (55.0\%) were eversmokers. For first-line chemotherapy, the median overall survival was 9.5 months and progression-free survival was 4.0 months, respectively. Twelve patients received pemetrexed-based chemotherapy and the overall response rate was $33.3 \%$ (4/12). Among four crizotinib-treated patients, one continued therapy for 8 months with the best response being disease stability. Conclusion: Given the poor clinical outcome and response to therapy for NSCLC, and the availability of promising anti-tumor MET inhibitors, screening for the MET exon 14 skip mutation should be incorporated into clinical practice.
\end{abstract}

This article is freely accessible online.

Correspondence to: Myung-Ju Ahn, MD, Ph.D., Division of Hematology-Oncology, Department of Medicine, Samsung Medical Center, Sungkyunkwan University School of Medicine, 81 Irwonro, Gangnam-gu, Seoul 06351, Republic of Korea. Tel: +82 234103438, Fax: +82 234123996, e-mail: silkahn@skku.edu or silk.ahn@samsung.com

Key Words: MET Exon 14 Skipping, NSCLC, crizotinib.
Lung cancer, including non-small cell lung cancer (NSCLC), is reported to be the leading cause of death from cancer in Korea (1). NSCLC accounts for approximately $85 \%$ of all cases of lung cancer (2). The identification of genetic abnormalities has dramatically changed the treatment landscape of NSCLC. Mutations in the epidermal growth factor receptor (EGFR) and anaplastic lymphoma kinase (ALK) rearrangements are the most clinically relevant targets. EGFR tyrosine kinase (TK) inhibitors have been shown to be effective in patients with specific tumor cell mutations in the EGFR TK domain (3). In addition, the newly developed ALK inhibitors -ceritinib, alectinib, and brigatinib- have been approved for ALK-positive NSCLC (4). With advances in technology, more oncogenic drivers, such as ROS1, RET, $B R A F, N T R K, M E T, N R G 1$, and others, can be identified using next generation sequencing (NGS) (5).

The MET proto-oncogene, located on chromosome 7q21q31, encodes the tyrosine kinase receptor for hepatocyte growth factor (HGF) (6). MET is activated when the HGF ligand binds to the MET receptor leading to homodimerization and phosphorylation of intracellular tyrosine residues (7). Dysregulation of the MET pathway in lung cancer arises due to gene mutation, amplification, and rearrangement, and protein overexpression $(5,8)$. Among them, MET exon 14 skipping gives rise to one of the most important oncogenic drivers. MET exon 14 encodes part of the juxtamembrane domain, containing the c-Cbl E3 ubiquitin ligase binding site, Y1003 (9). Because ubiquitination tags $M E T$ receptor for degradation, $M E T$ exon 14 skipping, which produces a truncated $M E T$ receptor lacking the ubiquitin binding site, results in decreased ubiquitination and sustained MET activation (10). MET exon 14 skipping occurs in 3-4\% (11) of patients with lung adenocarcinomas and is recognized 


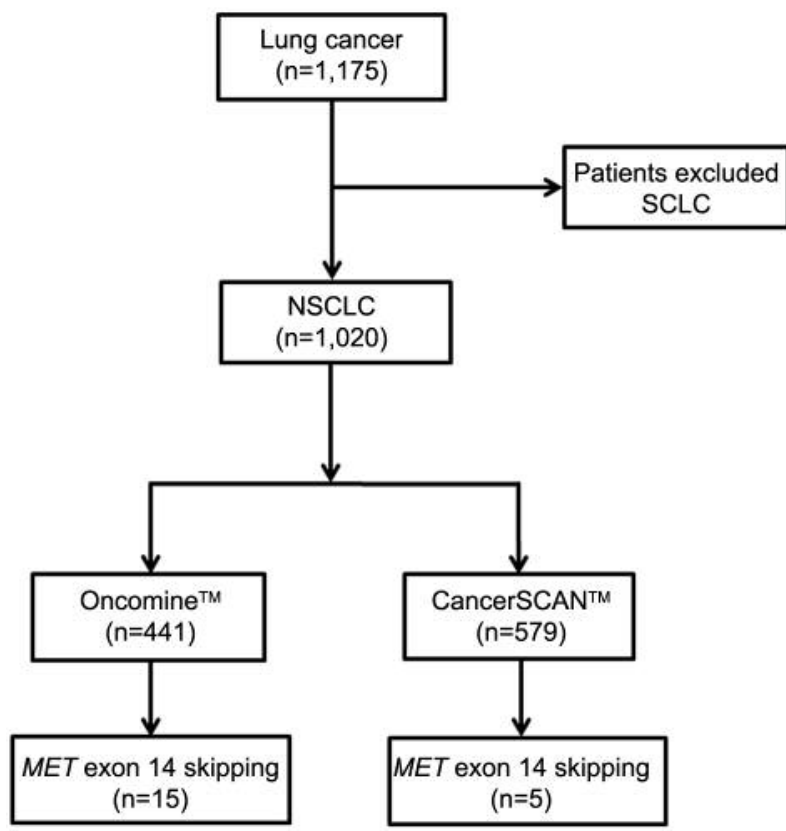

Figure 1. Flow-chart of patient selection. Samples were analyzed using Oncomine $^{T M}$ Focus Assay (n=441) or CancerSCAN ${ }^{T M}(n=579)$.

as a poor prognostic factor in patients with NSCLC; it has also been associated with a poor response to standard therapies (12). In this paper, we report a comprehensive analysis of clinical data from NSCLC patients harboring MET exon 14 skipping mutation in Korea.

\section{Patients and Methods}

Ethical statement. This study was approved by the institutional review board of the Samsung Medical Center (2019-07-194-002) and informed consent was waived.

Patients. A total of 1,020 patients who had been diagnosed with NSCLC were reviewed between January 2015 and July 2017 at the Samsung Medical Center. Clinical data, including patient characteristics, Eastern Cooperative Oncology Group (ECOG) performance status, surgery type, EGFR or ALK mutation, PDL1 expression and sites of metastasis, and response to chemotherapy or $M E T$ inhibitor, were retrospectively analyzed. Radiographic assessment of the response to chemotherapy or treatment with MET inhibitors was performed by a single physician (J.Y.H.) using RECIST 1.1 criteria (13).

Identification of MET exon 14 skipping. MET Exon 14 skipping was identified by NGS. Briefly, DNA and RNA were extracted from formalin-fixed paraffin-embedded or fresh biopsy tissue samples. Specimens with tumor tissues ( $>10 \%$ tumor content) were included in the study. In Figure 1, samples were analyzed using Oncomine ${ }^{\mathrm{TM}}$ Focus Assay (Thermo Fisher Scientific, San Francisco, CA, USA) (n=441) (14) or CancerSCAN ${ }^{\mathrm{TM}}$, a targeted sequencing platform established at
Table I. Baseline characteristics of patients with NSCLC.

\begin{tabular}{|c|c|}
\hline MET & on 14 skipping $(\mathrm{N}=20)$ \\
\hline \multicolumn{2}{|l|}{ Histologic type } \\
\hline Adenocarcinoma & $16(80 \%)$ \\
\hline Adenocarcinoma with sarcomatoid change & $1(5 \%)$ \\
\hline Pleomorphic carcinoma & $1(5 \%)$ \\
\hline Squamous cell carcinoma & $2(10 \%)$ \\
\hline \multicolumn{2}{|l|}{ Stage } \\
\hline I & $2(10 \%)$ \\
\hline II & $1(5 \%)$ \\
\hline III & $2(10 \%)$ \\
\hline IV & $15(75 \%)$ \\
\hline \multicolumn{2}{|l|}{ Gender } \\
\hline $\mathrm{F}$ & $8(40 \%)$ \\
\hline M & $12(60 \%)$ \\
\hline Median age at diagnosis, & $69(39-86)$ \\
\hline \multicolumn{2}{|l|}{ Smoking } \\
\hline Never smoker & $9(45 \%)$ \\
\hline Past smoker & $5(25 \%)$ \\
\hline Current smoker & $6(30 \%)$ \\
\hline \multicolumn{2}{|l|}{ ECOG performance status } \\
\hline $0-2$ & $19(95 \%)$ \\
\hline 3 & $1(5 \%)$ \\
\hline \multicolumn{2}{|l|}{$E G F R$ gene mutation } \\
\hline Wild type & $16(80 \%)$ \\
\hline NA & $4(20 \%)$ \\
\hline \multicolumn{2}{|l|}{$A L K$ fusion } \\
\hline Wild type & $20(100 \%)$ \\
\hline \multicolumn{2}{|l|}{ PD-L1 expression } \\
\hline Negative & $2(10 \%)$ \\
\hline Positive & $4(20 \%)$ \\
\hline NA & $14(70 \%)$ \\
\hline \multicolumn{2}{|l|}{ Operation } \\
\hline None & $15(75 \%)$ \\
\hline Lobectomy & $4(20 \%)$ \\
\hline Pneumonectomy & $1(5 \%)$ \\
\hline \multicolumn{2}{|l|}{ Metastatic sites } \\
\hline Bone & $8(40 \%)$ \\
\hline Pleura & $7(35 \%)$ \\
\hline Brain & $3(15 \%)$ \\
\hline Liver & $3(15 \%)$ \\
\hline Contralateral lung & $3(15 \%)$ \\
\hline Adrenal gland & $1(5 \%)$ \\
\hline Peritoneum & $1(5 \%)$ \\
\hline
\end{tabular}

F: Female; M: male; ECOG: Eastern Cooperative Oncology Group; EGFR: epidermal growth factor receptor; ALK: anaplastic lymphoma kinase; PD-L1: programmed death-ligand 1.

the Samsung Medical Center Genomic Institute ( $\mathrm{n}=579)$ (15). MET amplification was defined as a copy number greater than two.

MET immunohistochemistry (IHC). The BenchMark XT automated slide processing system (Ventana Medical Systems, Tucson, AZ, USA) was employed. The anti-MET (SP44) (Ventana Medical Systems, Tucson, AZ, USA) antibody was used for MET IHC staining. IHC data were categorized according to the following staining scores: 0 , negative; 1 , weak; 2 , moderate; and 3, strong (16). 


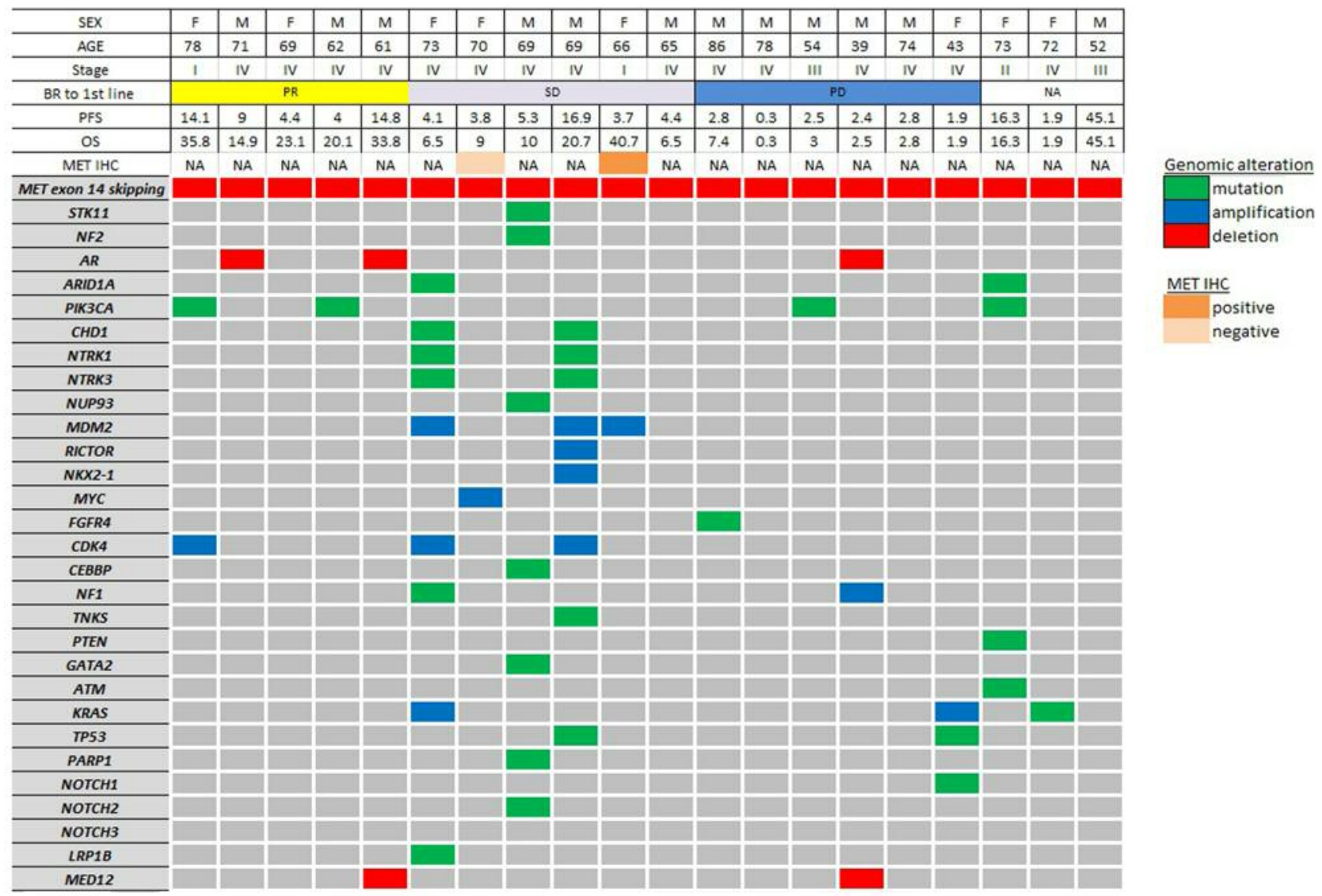

Figure 2. Genomic landscape of all patients with MET exon 14 skipping NSCLC. Concurring alterations, including PIK3CA mutation (4 patients), TP53 mutation (2 patients), KRAS amplification (2 patients), PTEN mutation (1 patient), and KRAS mutation (1 patient) were infrequently observed with MET exon 14 skipping NSCLC. Notably, patients with MET exon 14 skipping did not harbor concurrent EGFR, BRAF, ALK, ROS1 mutations, or RET translocations, suggesting that they are mutually exclusive.

Statistical analysis. Progression-free survival (PFS) was defined as the time from the date of first-line chemotherapy to the progression of cancer or death from any cause. Overall survival (OS) was defined as the period between the date of first-line chemotherapy and death from any cause. Survival curves were estimated by the Kaplan-Meier plot. All statistical analyses were performed using $\mathrm{R}$ software (version 3.2.3, $\mathrm{R}$ for Statistics Computing, Vienna, Austria).

\section{Results}

MET exon 14 skipping was identified in 20 NSCLC patients $(1.9 \%)$. The median age was 69 years (range $=39-86$ years), and $60.0 \%$ of the patients were male. Most patients $(55.0 \%)$ were ever-smokers. Adenocarcinoma was predominant $(85.0 \%)$, and we identified two cases (10.0\%) with squamous cell carcinoma and one case with pleomorphic carcinoma. Among 20 patients, $15(75.0 \%)$ had stage IV NSCLC at initial work-up. The most common metastatic site was bone $(40 \%)$, followed by the pleura $(35 \%)$ and brain (15\%). One of the five pleomorphic carcinoma (20\%) cases harbored MET exon 14 skipping. Four patients underwent lobectomy and one patient pneumonectomy. Most patients $(95.0 \%$ ) had ECOG performance status (PS) 0 to 2 . Four of the patients tested for programmed death ligand-1 (PD-L1) expression were positive. All patients were negative for $E G F R$ mutation and $A L K$ rearrangements as assayed by IHC (Table I).

The genomic landscape of the patients with MET exon 14 skipping NSCLC is shown in Figure 2. Notably, patients with $M E T$ exon 14 skipping did not harbor concurrent EGFR, BRAF, ALK, ROS1 mutations, or RET translocations, suggesting that they are mutually exclusive. In contrast, concurring alterations, including $P I K 3 C A$ mutation (4 patients), TP53 mutation (2 patients), SMAD4 mutation (2 patients), KRAS amplification (2 patients), PTEN mutation (1 patient), and KRAS mutation (1 patient) were infrequently observed with $M E T$ exon 14 skipping NSCLC. The MET IHC test was conducted in two patients. 


\section{A}

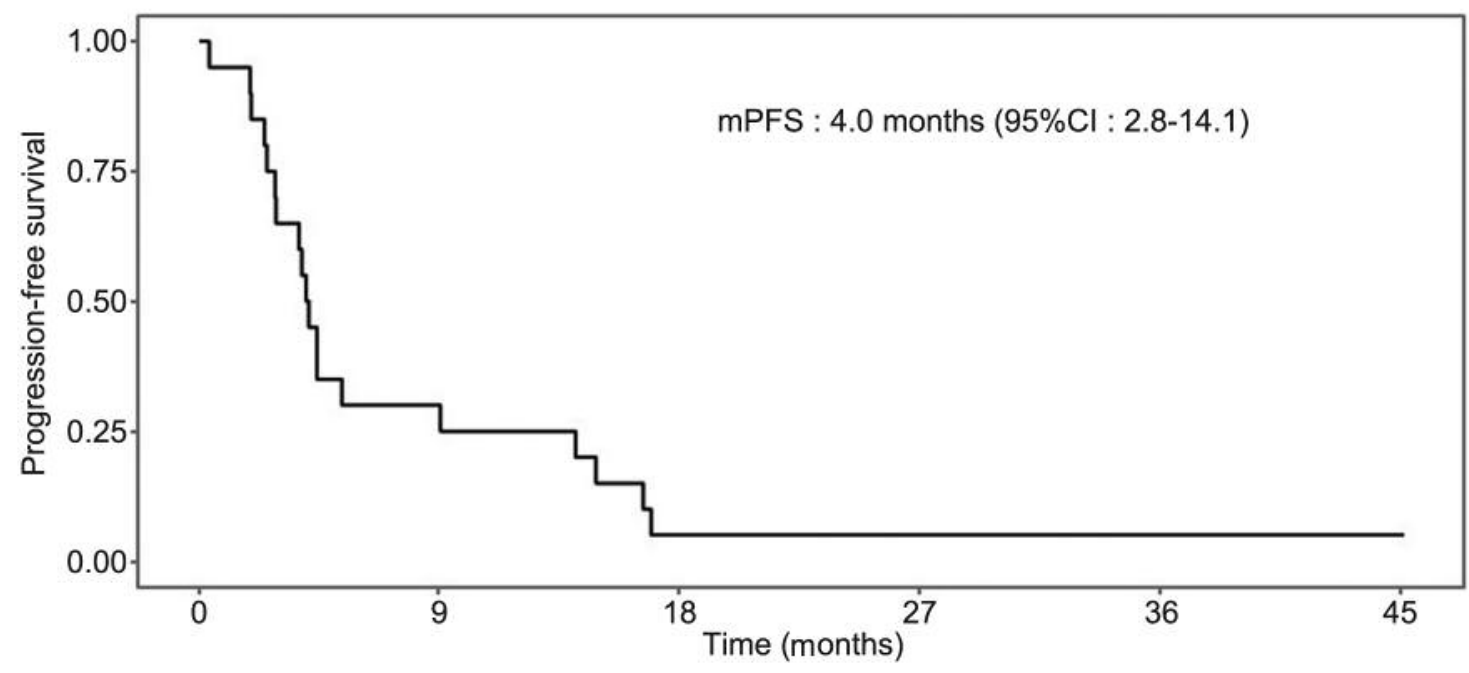

B

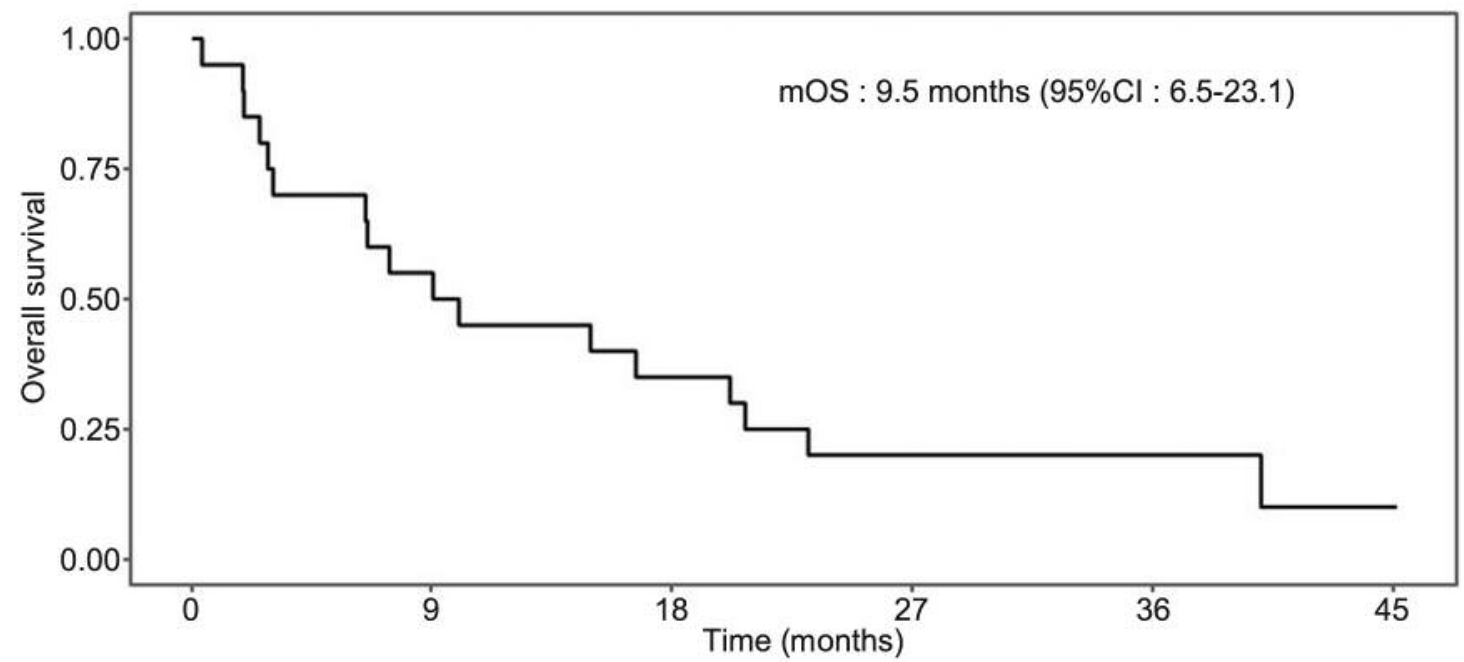

Figure 3. Kaplan-Meier plots of progression-free survival and overall survival for all patients. For first line chemotherapy, the median progressionfree survival (PFS) was 4.0 months [95\% confidence interval (CI)=2.8-14.1] (A) and the median overall survival (OS) was 9.5 months (95\%CI=6.523.1) (B).

Of the two patients, one patient was positive (membranous, $2+)$, and the other negative. No patient was tested using fluorescence in situ hybridization (FISH) to detect the MET amplification.

For first line chemotherapy, the median PFS was 4.0 months [95\% confidence interval $(\mathrm{CI})=2.8-14.1]$ (Figure 3A) and the median OS was 9.5 months $(95 \% \mathrm{CI}=6.5-23.1)$ (Figure 3B). In 12 patients treated with pemetrexed-based chemotherapy, the overall response rate was $33.3 \%$ (4/12). No patient had previous exposure to MET therapy as firstline chemotherapy.
Of the 20 patients with identified $M E T$ exon 14 alterations, four patients received orally crizotinib at a starting dose of 250 $\mathrm{mg}$, twice daily. Clinical and pathologic characteristics are summarized in Table II. A 69-year-old woman, never smoker who had been diagnosed with stage IV lung adenocarcinoma with brain metastasis, showed progression despite crizotinib as third-line chemotherapy (PFS, 9 days). A 62-year-old man with lung squamous cell carcinoma died 8 days after crizotinib was prescribed as fourth-line chemotherapy. A 39-year-old man with pleomorphic carcinoma died 4 days after crizotinib treatment as second-line chemotherapy. A 61-year-old man 

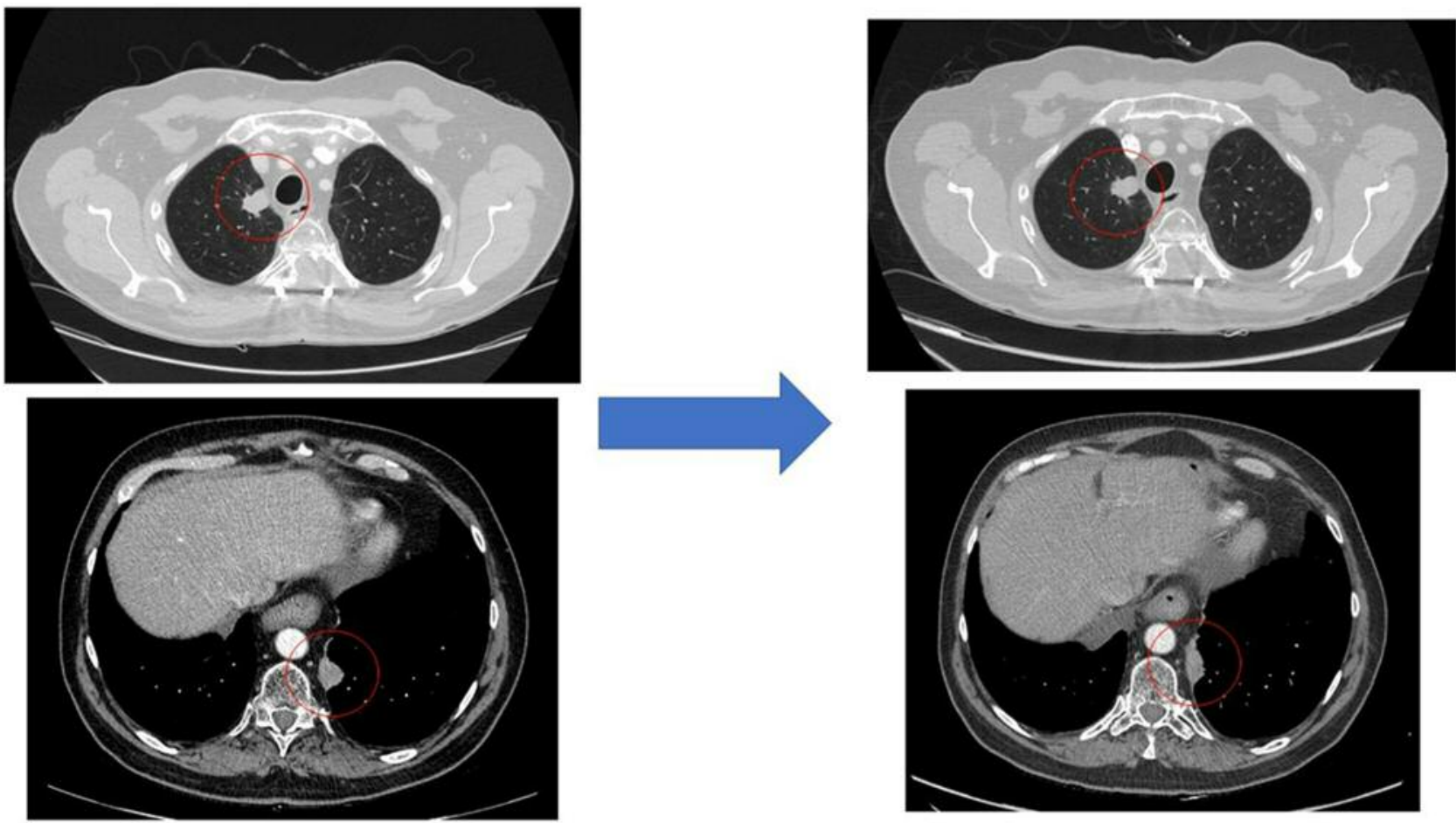

Oct 27, 2017

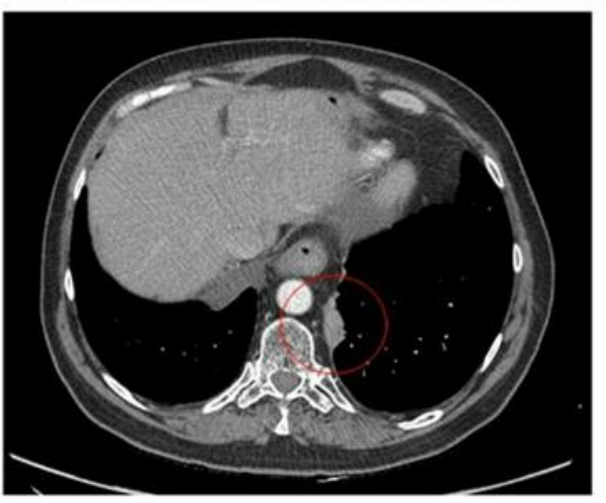

Jan 05, 2018

Figure 4. Computed tomography (CT) scans of a patient with MET exon 14 skipping showing the response while the patient was receiving crizotinib. CT scans obtained after 8 weeks of crizotinib treatment revealed a decreased subpleural metastatic lesion in the left lower lobe and unchanged tumor in the right upper lobe.

Table II. Clinical information and treatment outcomes of four patients who received crizotinib.

\begin{tabular}{lcccccccc}
\hline Gender & Age & MET inhibitor & CTx. Line & Initial stage & Smoking history & Histology & BR & PFS (days) \\
\hline F & 69 & Crizotinib & $3^{\text {rd }}$ & IV & Never-smoker & Adenocarcinoma & PD & 9 \\
M & 62 & Crizotinib & $4^{\text {th }}$ & IV & Ex-smoker & Squamous cell carcinoma & PD & 8 \\
M & 61 & Crizotinib & $2^{\text {nd }}$ & IV & Never-smoker & Adenocarcinoma & SD & 245 \\
M & 39 & Crizotinib & $2^{\text {nd }}$ & IV & Ex-smoker & Pleomorphic carcinoma & PD & 4 \\
\hline
\end{tabular}

CTx.: Chemotherapy; BR: best response; PFS: progression-free survival; PD: progressive disease; SD: stable disease; F: female; M: male.

presented with a thoracic spine compression fracture along with adenocarcinoma in the right upper lung; NGS revealed the $M E T$ exon 14 skipping mutation without other genomic alterations. The patient was treated with pemetrexed and carboplatin as first-line chemotherapy. After 14 months of first-line chemotherapy, $250 \mathrm{mg}$ crizotinib twice daily was initiated because of cancer progression. CT scans obtained after 8 weeks of crizotinib treatment revealed a decreased subpleural metastatic lesion in the left lower lobe and unchanged NSCLC in the right upper lobe (Figure 4). The patient continued therapy for 8 months with stable disease as the best response.

\section{Discussion}

In this study, we found that the incidence of MET exon 14 skipping in NSCLC was $1.9 \%$, which is lower than that $(3 \%)$ in previous studies (17). The overall incidence of MET mutations varies, occurring in $3 \%$ of squamous cell lung cancer and $3-8 \%$ of lung adenocarcinoma cases $(18,19)$. One study identified MET exon 14 mutations in 28 of 933 nonsquamous NSCLCs $(3.0 \%)$ (20). In another study of Korean patients, MET exon 14 skipping was detected in adenocarcinoma $(4.8 \% ; 11 / 230)$ and sarcomatoid carcinoma $(9.5 \% ; 2 / 21)$ cases by histology only (21). Liu et al. have 
reported that pulmonary sarcomatoid carcinoma is associated with a high incidence (approximately 22\%) of MET exon 14 skipping (22). The lower incidence of MET exon 14 skipping in our study might be partly attributed to the small number of patients with pleomorphic carcinoma $(5 / 1,020)$ enrolled.

$M E T$ exon 14 skipping occurred more frequently in older patients and ever-smokers. These findings are consistent with those of previous studies (16). Moreover, these are quite distinct clinical features compared to that of other patients with oncogenic drivers. Regarding the initial treatment, patients treated with platinum-based chemotherapy had short PFS (median PFS=4 months) and poor outcome (median OS=9.5 months). In a previous study, an 85-year-old man received four cycles of pemetrexed and carboplatin as the first-line chemotherapy for MET exon 14 skipping NSCLC, followed by one cycle of pemetrexed with maintenance chemotherapy, but the number of lung nodules were found to have increased (23).

Currently, a variety of MET tyrosine kinase inhibitors are being assessed in clinical trials. Crizotinib has been investigated in patients with $M E T$ exon 14 skipping NSCLC and showed a $32 \%$ response rate $(8 / 18)$ and a 9.1 month response duration, leading to its designation as breakthrough therapy by the Food and Drug Administration, USA (24). In our study, three of the four patients who were treated with crizotinib showed progression, and only one patient showed a durable response for more than 8 months. The lower response may be due to the enrollment of heavily pre-treated patients.

Capmatinib, an oral ATP-competitive, reversible, highly selective inhibitor of $M E T$ receptor tyrosine kinase, showed a $39.1 \%$ response rate among pretreated and $72 \%$ among treatment naive patients. Of note, a patient with brain metastasis experienced brain tumor shrinkage, suggesting that the drug penetrated in the CNS (25). Tepotinib, another highly selective MET inhibitor, demonstrated a $59.1 \%$ response rate with a 14.3-month response duration, and this drug has also been shown to have anti-brain tumor activity (26). Given their high selectivity, in contrast to previous drugs, most of these agents are quite effective.

Similar to other targeted agents, the development of acquired resistance is inevitable, and the exact mechanisms underlying this resistance have not yet been fully established. Resistance mechanisms include a secondary mutation in the tyrosine kinase domain, such as D1228N (27) or Y1230C (28), or activation of a bypass pathway, e.g., K-ras or EGFR amplification $(29,30)$. Further studies to determine the resistance to MET inhibitors are required.

There are several limitations to this study; it is a single cancer center study and involved a small sample size and retrospective data collection, which may have led to selection bias. Finally, most of the patients were not treated with other MET inhibitors, such as capmatinib, merestinib, or tepotinib.
In conclusion, MET exon 14 skipping was detected in $1.9 \%$ of Korean patients with NSCLC by NGS. MET exon 14 skipping occurred more frequently in older patients and ever-smokers. The median overall survival was limited to within 12 months. Given the poor clinical outcome and response to standard treatments for advanced non-small cell lung cancer, and the availability of $M E T$ inhibitors with promising anti-tumor activities, screening for the $M E T$ exon 14 skipping mutation should be incorporated into clinical practice.

\section{Conflicts of Interest}

The Authors have no conflicts of interest to declare regarding this study.

\section{Authors' Contributions}

Study design: HAJ, JMS, SHL, JSA; Study supervision: KP, MJA;Data collection: JYH, BMK; Data analysis: BMK, JHS; Statistical analysis: JYH; Manuscript preparation: JYH, MJA; Manuscript approval: all Authors.

\section{Acknowledgements}

This research was supported by the Collaborative Genome Program for Fostering New Post-Genome Industry of the National Research Foundation (NRF) funded by the Ministry of Science and ICT (MSIT) (No. NRF-2017M3C9A6044633).

\section{References}

1 Jung KW, Won YJ, Kong HJ and Lee ES: Prediction of cancer incidence and mortality in korea, 2019. Cancer Res Treat 51(2): 431-437, 2019. PMID: 30913864. DOI: 10.4143/crt.2019.139

2 Molina JR, Yang P, Cassivi SD, Schild SE and Adjei AA: Nonsmall cell lung cancer: Epidemiology, risk factors, treatment, and survivorship. Mayo Clin Proc 83(5): 584-594, 2008. PMID: 18452692. DOI: $10.4065 / 83.5 .584$

3 Lynch TJ, Bell DW, Sordella R, Gurubhagavatula S, Okimoto RA, Brannigan BW, Harris PL, Haserlat SM, Supko JG, Haluska FG, Louis DN, Christiani DC, Settleman J and Haber DA: Activating mutations in the epidermal growth factor receptor underlying responsiveness of non-small-cell lung cancer to gefitinib. N Engl J Med 350(21): 2129-2139, 2004. PMID: 15118073. DOI: 10.1056/NEJMoa040938

4 Spagnuolo A, Maione $\mathrm{P}$ and Gridelli C: Evolution in the treatment landscape of non-small cell lung cancer with alk gene alterations: From the first- to third-generation of alk inhibitors. Expert Opin Emerg Drugs 23(3): 231-241, 2018. PMID: 30251885. DOI: $10.1080 / 14728214.2018 .1527902$

5 The Cancer Genome Atlas Research Network: Comprehensive molecular profiling of lung adenocarcinoma. Nature 511: 543550, 2014. PMID: 25079552. DOI: 10.1038/nature13385

6 Drilon A, Cappuzzo F, Ou SI and Camidge DR: Targeting met in lung cancer: Will expectations finally be met? J Thorac Oncol 12(1): 15-26, 2017. PMID: 27794501. DOI: 10.1016/j.jtho. 2016.10 .014 
7 Skead G and Govender D: Gene of the month: Met. J Clin Pathol 68(6): 405-409, 2015. PMID: 25987653. DOI: 10.1136/ jclinpath-2015-203050

8 Ou SH, Kwak EL, Siwak-Tapp C, Dy J, Bergethon K, Clark JW, Camidge DR, Solomon BJ, Maki RG, Bang YJ, Kim DW, Christensen J, Tan W, Wilner KD, Salgia R and Iafrate AJ: Activity of crizotinib (pf02341066), a dual mesenchymalepithelial transition (met) and anaplastic lymphoma kinase (alk) inhibitor, in a non-small cell lung cancer patient with de novo met amplification. J Thorac Oncol 6(5): 942-946, 2011. PMID: 21623265. DOI: $10.1097 / J T O .0 b 013 \mathrm{e} 31821528 \mathrm{~d} 3$

9 Onozato R, Kosaka T, Kuwano H, Sekido Y, Yatabe Y and Mitsudomi T: Activation of met by gene amplification or by splice mutations deleting the juxtamembrane domain in primary resected lung cancers. J Thorac Oncol 4(1): 5-11, 2009. PMID: 19096300. DOI: 10.1097/JTO.0b013e3181913e0e

10 Kong-Beltran M, Seshagiri S, Zha J, Zhu W, Bhawe K, Mendoza N, Holcomb T, Pujara K, Stinson J, Fu L, Severin C, Rangell L, Schwall R, Amler L, Wickramasinghe D and Yauch R: Somatic mutations lead to an oncogenic deletion of met in lung cancer. Cancer Res 66(1): 283-289, 2006. PMID: 16397241. DOI: 10.1158/0008-5472.Can-05-2749

11 Drilon A: Met exon 14 alterations in lung cancer: Exon skipping extends half-life. Clin Cancer Res 22(12): 2832-2834, 2016. PMID: 27009743. DOI: 10.1158/1078-0432.Ccr-16-0229

12 Tong JH, Yeung SF, Chan AW, Chung LY, Chau SL, Lung RW, Tong CY, Chow C, Tin EK, Yu YH, Li H, Pan Y, Chak WP, Ng CS, Mok TS and To KF: Met amplification and exon 14 splice site mutation define unique molecular subgroups of non-small cell lung carcinoma with poor prognosis. Clin Cancer Res 22(12): 3048-3056, 2016. PMID: 26847053. DOI: 10.1158/ 1078-0432.Ccr-15-2061

13 Eisenhauer EA, Therasse P, Bogaerts J, Schwartz LH, Sargent D, Ford R, Dancey J, Arbuck S, Gwyther S, Mooney M, Rubinstein L, Shankar L, Dodd L, Kaplan R, Lacombe D and Verweij J: New response evaluation criteria in solid tumours: Revised recist guideline (version 1.1). Eur J Cancer 45(2): 228247, 2009. PMID: 19097774. DOI: 10.1016/j.ejca.2008.10.026

14 Williams HL, Walsh K, Diamond A, Oniscu A and Deans ZC: Validation of the oncomine ${ }^{\mathrm{TM}}$ focus panel for next-generation sequencing of clinical tumour samples. Virchows Arch 473(4): 489-503, 2018. PMID: 30105577. DOI: 10.1007/s00428-0182411-4

15 Shin HT, Choi YL, Yun JW, Kim NKD, Kim SY, Jeon HJ, Nam JY, Lee C, Ryu D, Kim SC, Park K, Lee E, Bae JS, Son DS, Joung JG, Lee J, Kim ST, Ahn MJ, Lee SH, Ahn JS, Lee WY, Oh BY, Park YH, Lee JE, Lee KH, Kim HC, Kim KM, Im YH, Park K, Park PJ and Park WY: Prevalence and detection of lowallele-fraction variants in clinical cancer samples. Nat Commun 8(1): 1377, 2017. PMID: 29123093. DOI: 10.1038/s41467-01701470-y

16 Lee GD, Lee SE, Oh DY, Yu Db, Jeong HM, Kim J, Hong S, Jung HS, Oh E, Song JY, Lee MS, Kim M, Jung K, Kim J, Shin YK, Choi YL and Kim HR: Met exon 14 skipping mutations in lung adenocarcinoma: Clinicopathologic implications and prognostic values. J Thorac Oncol 12(8): 1233-1246, 2017. PMID: 28502721. DOI: 10.1016/j.jtho.2017.04.031

17 Reungwetwattana T, Liang Y, Zhu V and Ou SI: The race to target met exon 14 skipping alterations in non-small cell lung cancer: The why, the how, the who, the unknown, and the inevitable. Lung Cancer 103: 27-37, 2017. PMID: 28024693. DOI: 10.1016/j.lungcan.2016.11.011

18 Paik PK, Drilon A, Fan PD, Yu H, Rekhtman N, Ginsberg MS, Borsu L, Schultz N, Berger MF, Rudin CM and Ladanyi M: Response to met inhibitors in patients with stage iv lung adenocarcinomas harboring met mutations causing exon 14 skipping. Cancer Discov 5(8): 842-849, 2015. PMID: 25971939. DOI: $10.1158 / 2159-8290 . C D-14-1467$

19 Lee C, Usenko D, Frampton GM, McMahon C, Ali SM and Weiss $\mathrm{J}$ : Met 14 deletion in sarcomatoid non-small-cell lung cancer detected by next-generation sequencing and successfully treated with a met inhibitor. J Thorac Oncol 10(12): e113-114, 2015. PMID: 26709483. DOI: 10.1097/jto.0000000000000645

20 Awad MM, Oxnard GR, Jackman DM, Savukoski DO, Hall D, Shivdasani P, Heng JC, Dahlberg SE, Janne PA, Verma S, Christensen J, Hammerman PS and Sholl LM: Met exon 14 mutations in non-small-cell lung cancer are associated with advanced age and stage-dependent met genomic amplification and c-met overexpression. J Clin Oncol 34(7): 721-730, 2016. PMID: 26729443. DOI: $10.1200 /$ jco.2015.63.4600

21 Kim EK, Kim KA, Lee CY, Kim S, Chang S, Cho BC and Shim HS: Molecular diagnostic assays and clinicopathologic implications of met exon 14 skipping mutation in non-small-cell lung cancer. Clin Lung Cancer 20(1): e123-e132, 2019. PMID: 30391211. DOI: 10.1016/j.cllc.2018.10.004

22 Liu X, Jia Y, Stoopler MB, Shen Y, Cheng H, Chen J, Mansukhani M, Koul S, Halmos B and Borczuk AC: Nextgeneration sequencing of pulmonary sarcomatoid carcinoma reveals high frequency of actionable met gene mutations. J Clin Oncol 34(8): 794-802, 2016. PMID: 26215952. DOI: 10.1200/ jco.2015.62.0674

23 Katakura S, Kobayashi N, Somekawa K, Masumoto N, Kudo M and Kaneko T: Non-small cell lung cancer with mesenchymalepithelial transition gene exon 14 skipping mutation treated with crizotinib. Respirol Case Rep 7(7): e00453, 2019. PMID: 31312453. DOI: $10.1002 / \mathrm{rcr} 2.453$

24 Drilon A, Clark J, Weiss J, Ou S, Camidge DR, Solomon B, Otterson G, Villaruz L, Riely G, Heist R, Shapiro G, Murphy D, Wang S, Usari T, Li S, Wilner K and Paik P: Updated antitumor activity of crizotinib in patients with met exon 14-altered advanced non-small cell lung cancer. J Thorac Oncol 13 (Suppl_10): S348, 2018. DOI: 10.1016/j.jtho.2018.08.300

25 Wolf J, Seto T, Han JY, Reguart N, Garon EB, Groen HJM, Tan DS, Hida T, de Jonge MJA, Orlov SV, Smit EF, Souquet PJ, Vansteenkiste JF, Giovannini M, Le Mouhaer S, Robeva A, Waldron-Lynch M and Heist RS: Results of the geometry mono1 phase II study for evaluation of the met inhibitor capmatinib (inc280) in patients (pts) with met delta ex14 mutated advanced non-small cell lung cancer (NSCLC). Ann Oncol 29(suppl_8), 2018. DOI: $10.1093 /$ annonc/mdy424.090

26 Felip E, Sakai H, Patel J, Horn L, Veillon R, Griesinger F, Bruns $\mathrm{R}$, Scheele $\mathrm{J}$ and Paik P: Phase ii data for the met inhibitor tepotinib in patients with advanced nsclc and met exon 14skipping mutations. J Thorac Oncol 13 (Suppl_10): S347, 2018. DOI: $10.1016 /$ j.jtho.2018.08.299

27 Heist RS, Sequist LV, Borger D, Gainor JF, Arellano RS, Le LP, Dias-Santagata D, Clark JW, Engelman JA, Shaw AT and Iafrate AJ: Acquired resistance to crizotinib in nsclc with met exon 14 skipping. J Thorac Oncol 11(8): 1242-1245, 2016. PMID: 27343442. DOI: $10.1016 /$ j.jtho.2016.06.013 
28 Awad MM, Leonardi GC, Kravets S, Dahlberg SE, Drilon AE, Noonan S, Camidge DR, Ou S-HI, Costa DB, Gadgeel SM, Steuer CE, Forde PM, Zhu VW, Fukuda YK, Clark JW, Janne PA, Mok T, Sholl LM and Heist RS: Impact of met inhibitors on survival among patients (pts) with met exon 14 mutant (metdel14) non-small cell lung cancer (NSCLC). J Clin Oncol 35: 8511-8511, 2017. DOI: 10.1200/JCO.2017.35.15_suppl.8511

29 Bahcall M, Awad MM, Sholl LM, Wilson FH, Xu M, Wang S, Palakurthi S, Choi J, Ivanova EV, Leonardi GC, Ulrich BC, Paweletz CP, Kirschmeier PT, Watanabe M, Baba H, Nishino M, Nagy RJ, Lanman RB, Capelletti M, Chambers ES, Redig AJ, VanderLaan PA, Costa DB, Imamura $\mathrm{Y}$ and Janne PA: Amplification of wild-type kras imparts resistance to crizotinib in met exon 14 mutant non-small cell lung cancer. Clin Cancer Res 24(23): 5963-5976, 2018. PMID: 30072474. DOI: 10.1158/10780432.Ccr-18-0876

30 Qi J, McTigue MA, Rogers A, Lifshits E, Christensen JG, Janne PA and Engelman JA: Multiple mutations and bypass mechanisms can contribute to development of acquired resistance to met inhibitors. Cancer Res 71(3): 1081-1091, 2011. PMID: 21266357. DOI: 10.1158/0008-5472.Can-10-1623

Received January 22, 2020

Revised February 4, 2020

Accepted February 7, 2020 